\title{
Contested Epidemics: Policy Response in Brazil and the U.S. and what the BRICS Can Learn*
}

\author{
by Jeni Vaitsman \\ Fundação Oswaldo Cruz, Brazil
}

(Gómez, Eduardo J.. Contested Epidemics: Policy Response in Brazil and the U.S. and what the BRICS Can Learn. London: Imperial College Press, 2015)

No country responds to epidemics in the same way. What makes some countries to be more successful than others in coping with epidemics? It is this question which Eduardo Gómez (2015) tries to answer in his research. He compares the responses that have been given by the United States and Brazil, since the early twentieth century, to the emergence of what he calls contested epidemics, such as syphilis, polio, AIDS, tuberculosis, malnutrition and, currently, obesity.

Contested epidemics usually imply political views, proposals and conflicting interests between leaders, bureaucrats and civil society, and governments usually do not quickly react before their emergence. When they are associated with behaviors such as AIDS, syphilis and alcoholism or have an incidence over poor and marginalized groups, moral beliefs often guide the perceptions of decision makers and other stakeholders on their potentiality to become a threat to society.

Walking away from analyses that suggest that mature democracies with stable democratic institutions and with health systems with more financial and technological resources respond in a better way to epidemics, Gómez (2015) argues that not all the responses depend on the type of political regime or on the resources invested in health. Non-democratic or less developed countries, with more limited resources and infrastructure, often respond to epidemics in a way as effective as -or more effective than- richer countries.

(*) http://dx.doi.org/10.1590/1981-38212016000300009 
It is a thorough work that seeks to answer, through a comparative analysis, to two central questions related to what different theories and models from the field of public policy say about the policymaking process: What makes a problem eligible for being included into the political agenda and becoming an object of governmental decision? Which are the conditions for the success of the implemented policies?

Methodologically, the author relies on the Most Similar Systems Design (MSSD), a tool that compares, in the cases that studies, similar contextual variables, indicating causal relationships and different results. The purpose of the comparison is to point out the historical, political and social singularities that produced institutional and political responses to the epidemics. Both countries underwent significant social, political, economic and scientific-technological changes in the long period analyzed, both on the domestic and international level. Even so, Gómez (2015) manages to identify certain patterns of responses, whose explanation is sought in the historical trajectories of both countries.

As preconditions for the governments to respond to an epidemic -the problem of the agenda and the decision-making-, he emphasizes: the interest of the presidents, their personal beliefs and ambitions, especially at the global level; and threats to national security. As for the success of the responses, he shows that they depend on conditions that are not related to the personal interest of the presidents: the existence of a centralized bureaucracy able to coordinate the interventions; and the role of civil society in the institutional political context of the countries. These variables are considered as crucial for the implementation of policies conducting to the response.

In the US, the government's responses to epidemics and diseases only became priority and were centralized when presidents got personally interested in the problem or when the problem became a threat to national security, affecting military recruitment or economy. Since the beginning of the twentieth century, the American civil society played an important role on various health problems, such as syphilis, malnutrition, polio; its role did not, nonetheless, involved a centralized government response. During World War II, malnutrition was posed as a threat, but while the government's focus of action was Army's capacity, the civil society organizations advocated for better nutrition and for the control of food processing by the industry. Their goal was to influence government and society, but the lobby of the industry always managed to veto various 
aspects of regulation. This same situation would be repeated decades later with the emergence of obesity.

In Brazil, since the beginning of the twentieth century, the fight against tuberculosis by the central government was a demand of the medical and intellectual elites; however, the centralized response only came in 1930, with President Vargas, who initiated the construction of Modern bureaucracy. This is a defining moment in the Brazilian history because it established the centralization of all sectors and territorial levels, as a state organization principle.

In the case of AIDS, at its inception in the US, there was a lot of resistance, associated with Reagan and Bush's moral issues. This resulted in, among other things, the prohibition of HIV-positive immigrants and in the official absence of international conferences on the topic. Despite its scientific and technological advantages, the US did not invest in a centralized bureaucracy that responded, with public policies, to the problem. Several agencies contended the main role without any central coordination. Partnerships with other countries also depended on the American medical, economic or military interests, or on the American political leaders. The American agenda was rather isolationist, in terms of developing its own solutions for its health problems and exporting them to other countries.

The author argues that even though the US is the world's leading actor in the financial and technique provisions to face epidemics, contributing in the case of AIDS with more than $50 \%$ of the global funding, the Brazilian response to the epidemic was more successful. How was this possible?

In Brazil presidents Fernando Henrique Cardoso (FHC) and Lula, along with officials from the Ministry of Health and other elites, wanted to demonstrate to the international community that Brazil could join industrialized countries not only in the fight against AIDS, but also against tuberculosis, which resurfaced at the end of the twentieth century. Stronger national government responses that also extended to the fight against tuberculosis were a result of international growing criticism and pressure, and not of domestic pressure from civil society.

For the author, the Brazilian response suggests that the incentives for a centralized response often do not reside at the domestic level, but at the international one. FHC and Lula were interested in building an international reputation for Brazil. And there was a strategy in accordance. The World Bank loan in 1994 for strengthening the 
Brazilian AIDS program was crucial in this sense, because it provided the means by which Brazil built its international reputation. The policymaking to fight against AIDS would have also been a means for alternative political purposes.

The success of the Brazilian policy is assigned to the role of a centralized bureaucracy that Brazil managed to articulate with civil society, both in the case of AIDS and tuberculosis. Gómez (2015) recognizes the role of sanitaristas and of the political view stating that the fight against epidemics depends on a technical staff and on a centralized bureaucracy, but he also acknowledges that this success was guaranteed through the cooperation with civil society. For him, it was not the pressure of civil society over the state, as proposed by the literature of the interest group, but the state itself which succeeded to make civil society working to achieve its goals, which made its demands to be met. When AIDS epidemic came, the technicians from the Ministry of Health strategically sought and used this civic support in order to increase their legitimacy, and to influence and to achieve political and financial support in Congress. In the US, the CDC professionals neither had political support to undertake centralized strategies, nor had access to civic supporters.

The study provides two major contributions to the analysis of health policies: first, analyzing specific issues in national contexts in certain periods, although in a diachronic perspective; second, showing how two countries developed certain patterns of responses from institutional contexts with two variables coming into play: the existence of a centralized bureaucracy, and the articulation of that bureaucracy with civil society. The way in which, in different contexts, the actors entering into the setting of these variables are related, produced different results.

Brazil, from the point of view of the historical conditions for the construction of these variables, had, in the 90s, a technical and professional elite coming from the sanitarista movement and from graduate programs, which turned out to be a part of the Ministry of Health in building the recently approved, by the Constitution of 1988, Unified Health System (SUS). It was a time of great social and political mobilization in which non-governmental organizations also expanded and professionalized. Although the decade was marked by economic downturn and fiscal restraint, values-driven-policies in defense of diversity and combat of prejudice -which was crucial in the case of AIDS-, advanced in the health sector. Participatory mechanisms established in the SUS, and actions of movements and organizations fighting for the rights of women, black people, 
and homosexuals, came together in a context of horizontal governance in which relations of cooperation between the officials from the Ministry of Health and a diverse set of actors for the implementation of health programs, were established.

As for what BRICS might learn in terms of institutional and policy lessons from Brazil, this is a matter of compared policy analysis that deserves further examination. Deficits and centralization excesses, democracy, civil society participation in policies, normative principles of the state and values, are the result of long historical and social processes of institutional and political construction. In addition to the common interest of countries in this group to ensure a weightier international role, the issues raised can guide a broad research agenda.

As a final note, some absences of the cited references in the text should be revised in a second edition.

Translated by Cabo Verde 